\title{
EFICIÊNCIA DO ÓLEO DE CANDEIA NA MELHORIA DA RESISTÊNCIA DA MADEIRA DE SUMAÚMA A CUPINS
}

\author{
Juarez Benigno Paes ${ }^{1}$, Clécio Maynard Bastista da Fonsêca ${ }^{2}$, Carlos Roberto de Lima ${ }^{3}$, Ademilson Daniel de Souza ${ }^{3}$
}

(recebido: 15 de maio de 2008; aceito: 31 de março de 2010)

\begin{abstract}
RESUMO: Nesta pesquisa, objetivou-se avaliar a eficiência do óleo de candeia (Eremanthus erythropappus (DC.) Macleish.), na melhoria da resistência da madeira de sumaúma (Ceiba pentandra (L.) Gaertn.) ao cupim xilófago Nasutitermes corniger (Motsch.), em ensaios de laboratório. Utilizaram-se corpos-de-prova com dimensões nominais de 0,7 x 2,0 x 2,5 cm (espessura x largura $\mathrm{x}$ comprimento) para o ensaio de alimentação forçada e de 0,7 x 2,0 x 10,2 cm (espessura x largura x comprimento) para o de preferência alimentar. As amostras foram tratadas pelo processo de imersão a frio e atingiram retenções médias de 10,61; 16,73; 22,04; e 26,94 kg de óleo $/ \mathrm{m}^{3}$ de madeira (ensaio de alimentação forçada) e de 38,35; 58,22; 87,53; e 108,36 kg de óleo/m³ de madeira (ensaio de preferência alimentar), e submetidas ao ataque do cupim Nanutitermes corniger, durante 28 e 20 dias para os ensaios de alimentação forçada e preferência alimentar, respectivamente. Constatou-se que o óleo de candeia nas retenções de $10,61 \mathrm{~kg} / \mathrm{m}^{3}$ (ensaio de alimentação forçada) e de $38,35 \mathrm{~kg} / \mathrm{m}^{3}$ (ensaio de preferência alimentar), inibiu o ataque dos cupins e as retenções de $16,73 \mathrm{~kg} / \mathrm{m}^{3}$ (ensaio de alimentação forçada) e de $58,22 \mathrm{~kg} / \mathrm{m}^{3}$ (ensaio de preferência alimentar) preveniram o ataque à madeira tratada, inviabilizando o acesso dos cupins à fonte de alimento.
\end{abstract}

Palavras-chave: Óleo de candeia, tratamento da madeira, ensaios biológicos.

\section{Eremanthus erythropappus OIL EFFICIENCY TO IMPROVEMENT OF Ceiba pentandra WOOD RESISTANCE TO TERMITES}

\begin{abstract}
The research evaluated the efficiency of Eremanthus erythropappus (DC.) Macleish. oil to improve the resistance of Ceiba pentandra (L.) Gaertn. wood to Nasutitermes corniger Motsch. termite under laboratory condition. Wood samples with nominal dimensions of $0.7 \times 2.0 \times 2.5 \mathrm{~cm}$ (thickness $x$ width $\times$ length), forcedfeeding assay and of $0.7 \times 2.0 \times 10.2 \mathrm{~cm}$ (thickness $x$ width $\times$ length), alimentary preference assay were treated by cold immersion process and reached medium retentions of $10.61 ; 16.73 ; 22.04 ;$ and $26.94 \mathrm{~kg}$ of oil// $\mathrm{m}^{3}$ of wood (force feeding) and of 38.35; 58.22; 87.53; e $108.36 \mathrm{~kg}$ of oil/ $/ \mathrm{m}^{3}$ of wood (preference feeding) and submitted to Nasutitermes corniger termite attack during 28 (force feeding) and 20 days (alimentary preference). The results showed that the Eremanthus erythropappus oil in the retentions of $10.61 \mathrm{~kg} / \mathrm{m}^{3}$ (forced feeding) and $38.35 \mathrm{~kg} / \mathrm{m}^{3}$ (preference feeding) inhibited the attack and in the retentions of $16.73 \mathrm{~kg} / \mathrm{m}^{3}$ (force feeding) and of $58.22 \mathrm{~kg} / \mathrm{m}^{3}$ (preference feeding) prevented the attack in wood samples, making unfeasible the access of the termites to the food source.
\end{abstract}

Key words: Eremanthus erytropappus oil, wood treatment, biologic assays.

\section{INTRODUÇÃO}

A candeia é uma árvore da família Asteraceae, pertencente ao grupo ecológico das pioneiras, sendo considerada precursora na colonização de campos. Ela se desenvolve rapidamente em campos abertos, formando povoamentos mais ou menos puros. Existem várias espécies de candeia, porém a Eremanthus erythropappus (DC.) Macleish e a Eremanthus incanus (Less.) Less são as de maior importância econômica e de maior ocorrência em Minas Gerais (SCOLFORO et al., 2004).
A Eremanthus erythropappus se desenvolve em sítios com solos pouco férteis, rasos e, predominantemente em áreas de campos de altitude, os quais variam entre 900 e 1.700 m. É uma espécie de múltiplos usos, porém sua madeira é mais utilizada para moirão de cerca, pela sua durabilidade e para a produção de óleo essencial, cujo principal componente, o alfabisabolol (álcool sesquiterpênico insaturado e opticamente ativo, obtido da destilação direta de óleos naturais), possui propriedades antiflogísticas, antibacterianas, antimicóticas, dermatológicas e espasmódicas (SCOLFORO et al., 2004).

\footnotetext{
${ }^{1}$ Engenheiro Florestal, D.Sc. - Departamento de Engenharia Florestal - Universidade Federal do Espírito Santo - Av. Governador Lindemberg, 316, Centro - 29550-000 - Jerônimo Monteiro, ES - jbp2@uol.com.br

${ }^{2}$ Engenheiro Florestal - Unidade Acadêmica de Engenharia Florestal - Universidade Federal de Campina Grande - Cx. P. 64 - $58700-970$ Patos, PB - cleciomaynard@ @otmail.com,dsouzaig@gmail.com

${ }^{3}$ Engenheiro Florestal, M.Sc. - Unidade Acadêmica de Engenharia Florestal - Universidade Federal de Campina Grande - Cx. P. 64 58700-970 - Patos, PB - crlima16@hotmail.com
} 
A Eremanthus incanus ocorre em áreas de Cerrado, de florestas secundárias e na Caatinga, com ocorrência predominante na faixa de 650 a $1.200 \mathrm{~m}$ de altitude. É mais utilizada para a produção de moirão, uma vez que produz óleo essencial de baixa qualidade contendo menos alfabisabolol (SCOLFORO et al., 2002).

Os moirões de candeia são procurados pelos produtores rurais, em função da boa resistência natural apresentada, sendo comercializados, conforme informações obtidas junto a Universidade Federal de Lavras (UFLA), em 30 de abril de 2008, ao custo de $\mathrm{R} \$ 80,00$ a R \$ 110,00 a dúzia. Sua resistência natural pode estar associada ao teor de óleo existente na madeira, tendo as peças de maior diâmetro e idade um maior teor de óleos e, consequentemente, uma maior durabilidade natural.

Os produtos obtidos da candeia alcançam preços relativamente altos no mercado. Por exemplo, as indústrias que extraem o óleo essencial pagam entre R\$50,00 e R\$ 90,00 pelo metro estéreo de madeira. O óleo de candeia natural bruto é comercializado nos mercados nacionais e internacionais, podendo alcançar até US\$27.00 o quilo (SCOLFORO et al., 2002).

Nesse sentido, com o dólar comercial cotado a 1,685 reais (30 de abril de 2008), o custo da quantidade de óleo necessário para o tratamento de um moirão de eucalipto de $12 \mathrm{~cm}$ de diâmetro e 2,0 metros de comprimento, com $70 \%$ de alburno, tratado com retenção de $10 \mathrm{~kg}$ de óleo $/ \mathrm{m}^{3}$ de madeira, ficaria em média $\mathrm{R} \$ 7,60$. Esse valor está próximo do preço pago pelos moirões de candeia no sul de Minas Gerais que varia de $\mathrm{R} \$ 6,67$ a 9,17 a unidade. Porém, ao valor do óleo, para o caso apresentado, deveriam ser acrescidos os custos com o tratamento e os da própria madeira.

A maioria das madeiras comercializadas, a exemplo da sumaúma (Ceiba pentandra (L.) Gaertn.), não apresenta uma boa durabilidade natural. A durabilidade pode ser melhorada por meio da adição de produtos químicos e tratamentos que lhes proporcionem uma maior proteção, protegendo, assim, os recursos florestais, o que é de fundamental importância ecológica e econômica, pois o alívio da pressão sobre as florestas remanescentes permite a formação de madeiras com maior dimensão, as quais podem ser utilizadas para fins mais nobres (FARIAS SOBRINHO, 2003).

Nos dias atuais, a humanidade tem se preocupado em utilizar produtos de fontes renováveis, visando à diminuição da agressividade ao meio ambiente proporcionado por produtos advindos de fontes não- renováveis. Nesse sentido, o emprego do óleo de candeia para incrementar a vida útil de artigos de madeira é uma opção para a substituição de produtos atualmente utilizados no tratamento da madeira, pois, a utilização do óleo de candeia pode ser justificada para fins mais nobres, como na construção civil e em outros usos em que um produto possa agregar resistência à madeira sem causar danos ao ambiente e à saúde humana.

Os cupins são, dentre os insetos, os mais severos agentes destruidores da madeira (PAES \& VITAL, 2000), sendo os de solos, ou subterrâneos, os responsáveis pelos maiores volumes de perdas de madeira no mundo (HUNT \& GARRATT, 1967; RICHARDSON, 1993).

No Semiárido brasileiro, os cupins do gênero Nasutitermes são capazes de invadir, com sucesso, o meio urbano, atacando móveis e outros objetos construídos com madeira, como batentes de portas e janelas e, principalmente, madeiras empregadas nas estruturas das construções (PAES et al., 2003, 2006a).

Para testar a resistência natural de madeiras e de produtos utilizados no tratamento preservativo contra cupins subterrâneos, são executados em laboratório dois tipos de ensaios: o ensaio normatizado pela norma D 3345 da American Society for Testing and Materials - ASTM (2005b) e Associação Francesa de Normalização (AFNOR NFX - 41-539), citado por Paes (1997), conhecido por ensaio de alimentação forçada e o proposto por Supriana (1985), denominado de ensaio de preferência alimentar.

Em seu trabalho, Supriana (1985) apresenta algumas críticas aos métodos normalizados pela ASTM D - 3345 e AFNOR - NFX - 41-539 e considera que, quando as madeiras são oferecidas em conjunto aos cupins, os resultados são mais próximos da realidade.

Conduziu-se esta pesquisa, com o objetivo de avaliar a eficiência do óleo de candeia (Eremanthus erythropappus (DC.) Macleish.) na melhoria da resistência da madeira de sumaúma (Ceiba pentandra (L.) Gaertn.) ao cupim xilófago Nasutitermes corniger Motsch. em condições de laboratório.

\section{MATERIAL E MÉTODOS}

\subsection{Obtenção do óleo de candeia, confecção e tratamento dos corpos-de-prova}

O óleo utilizado para o tratamento dos corpos-de-prova foi cedido pela indústria Citróleo Comércio e Indústria Ltda, situada em Carrancas - MG.

Para a confecção dos corpos-de-prova foi empregada uma peça de sumaúma (Ceiba pentandra (L.) 
Gaerth.) com 3,5 cm de espessura e 200 centímetros de comprimento, obtida em uma marcenaria localizada no município de Patos - PB.

As amostras para os ensaios de alimentação forçada foram confeccionadas com dimensões de $0,7 \times 2,0 \times 2,5 \mathrm{~cm}$ (espessura $\mathrm{x}$ largura $\mathrm{x}$ comprimento) e para o de preferência alimentar com dimensões de 0,7 x 2,0 x 10,2 cm (espessura x largura $\mathrm{x}$ comprimento).

Os corpos-de-prova obtidos foram selecionados ao descartar aqueles que apresentavam defeitos, lixados e identificados convenientemente em função da retenção e do ensaio a ser empregado. As amostras selecionadas foram secas em estufa a $103 \pm 2{ }^{\circ} \mathrm{C}$, até massa constante e tiveram a massa seca e o volume, obtidos conforme o recomendado pela ASTM D - 1413 (ASTM, 2005a) e os valores utilizados no cálculo da retenção dos óleos na madeira e da perda de massa causada pelos cupins xilófagos.

Foram realizados ensaios preliminares para detectar os tempos de imersão necessários no óleo de candeia para as amostras atingirem as retenções metas desejadas de 10, 15,20 e $25 \mathrm{~kg} / \mathrm{m}^{3}$ (ensaio de alimentação forçada) e de 35 , 60,85 e $105 \mathrm{~kg} / \mathrm{m}^{3}$ (ensaio de preferência alimentar). As amostras foram tratadas pelo processo de imersão a frio.

Além dos corpos-de-prova confeccionados com a madeira de sumaúma, foram utilizados, por exigência da norma ASTM D - 3345 (ASTM, 2005b), corpos-de-prova não-tratados de madeira de Pinus sp.

\subsection{Ensaios de resistência a cupins xilófagos}

Para testar a eficiência do óleo de candeia a cupins xilófagos, empregaram-se os ensaios de alimentação forçada (ASTM, 2005a) e de preferência alimentar, realizado conforme a metodologia descrita por Paes et al. (2006b, 2007) e Supriana (1985).

A colônia de cupins utilizada nos experimentos foi coletada nas proximidades do Laboratório de Tecnologia de Produtos Florestais, Campus da Universidade Federal de Campina Grande, em Patos - PB (latitude 701'28' Sul, longitude $37^{\circ} 16^{\prime} 48^{\prime}$ ' Oeste e altitude $242 \mathrm{~m}$ ).

A perda de massa sofrida pelos corpos-de-prova em função do ataque dos cupins foi corrigida por meio de amostras submetidas às mesmas condições de ensaio, porém sem a presença de cupins (perda de massa operacional).

\subsubsection{Ensaio de alimentação forçada}

O ensaio foi executado segundo a ASTM D - 3345 (ASTM, 2005b), com algumas modificações sugeridas por
Paes (1997). Assim, o experimento foi montado em frascos de $500 \mathrm{~mL}$, preenchidos com $200 \mathrm{~g}$ de areia cuja umidade foi corrigida para $75 \%$ da capacidade de retenção de água pela adição de $36 \mathrm{~mL}$ de água destilada (Figura 1).

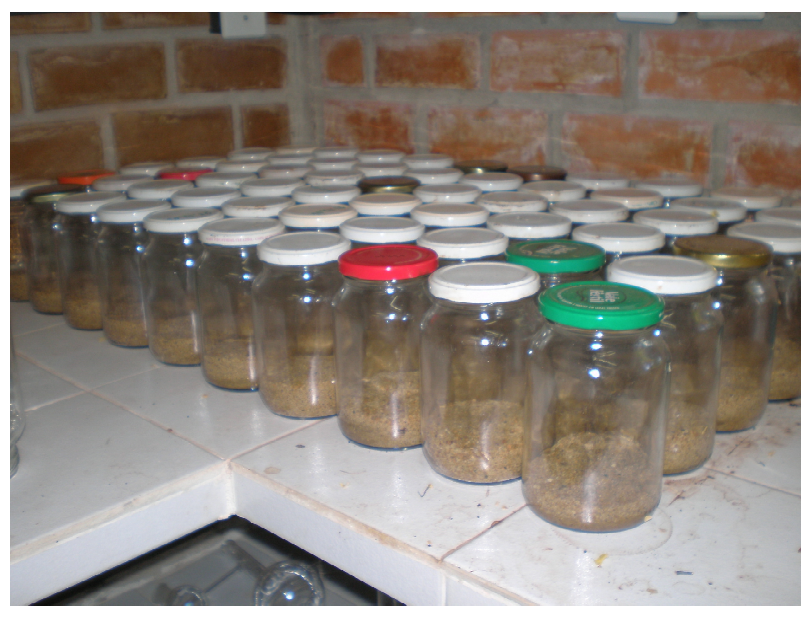

Figura 1 - Frascos preparados para o ensaio de alimentação forçada.

Figure 1 -Bottles prepared for the forced feeding assay.

Em cada frasco, foram adicionados um corpo-de-prova e $1 \pm 0,05 \mathrm{~g}$ de Nasutitermes corniger Motsch., equivalente $\mathrm{a} \pm 390$ indivíduos, contendo aproximadamente, $80 \%$ de operários (proporção existente na colônia).

Após a adição dos cupins, os frascos foram levemente tampados, para evitar a fuga e permitir a circulação de ar. Foram montadas sete repetições para cada retenção, em um delineamento inteiramente casualizado. $\mathrm{O}$ ensaio permaneceu em sala climatizada $\left(28 \pm 2{ }^{\circ} \mathrm{C}\right.$ e $75 \pm 5 \%$ de umidade relativa) por 28 dias.

Para se avaliar a atividade e o vigor dos insetos, conforme o indicado pela ASTM D - 3345 (ASTM, 2005b), foram montados sete frascos controle, contendo areia e os insetos e outros três para cada retenção, para avaliação da perda de massa operacional, contendo areia e corpos-deprova sem a presença dos cupins.

A eficiência do tratamento com óleo de candeia foi avaliada em função da perda de massa (\%) e do desgaste (nota) das amostras de sumaúma, da mortalidade dos cupins (\%) (Tabela 1) e do tempo (dias) para a morte dos cupins. A perda de massa foi avaliada com base na massa seca dos corpos-de-prova, tomada antes e após o ensaio e corrigida em função da perda de massa operacional.

Cerne, Lavras, v. 16, n. 2, p. 217-225, abr./jun. 2010 
Tabela 1 - Avaliação do desgaste da madeira e da mortalidade dos cupins (ASTM, 2005b).

Table 1 - Evaluation of wood waste and mortality of termites (ASTM, 2005b).

\begin{tabular}{lc}
\hline Tipo de Desgaste & Notas \\
\hline Sadio, permitindo escarificações superficiais & 10 \\
Ataque superficial & 9 \\
Ataque moderado, havendo penetrações & 7 \\
Ataque intensivo & 4 \\
Falha, havendo ruptura dos corpos-de-prova & 0 \\
\hline Mortalidade & $(\%)$ \\
\hline Baixa & 0 - 33 \\
Moderada & $34-66$ \\
Alta & $67-99$ \\
Total & 100 \\
\hline
\end{tabular}

\subsubsection{Ensaio de preferência alimentar}

Para a montagem do ensaio os corpos-de-prova foram dispostos em uma caixa de $250 \mathrm{~L}$, que continha uma camada de aproximadamente $10 \mathrm{~cm}$ de areia úmida. A caixa foi apoiada sobre quatro blocos cerâmicos postos em bandejas de plástico, de 30 × 40 × $5 \mathrm{~cm}$, contendo água, para evitar a fuga dos cupins.

Os corpos-de-prova foram distribuídos na caixa segundo um delineamento em blocos casualizados, contendo 7 repetições (blocos), 4 retenções, além de 7 amostras de sumaúma não-tratadas (testemunhas, retenção zero) e 7 amostras de Pinus sp. (conforme recomendações da D - 3345 (ASTM, 2005b)), totalizando 42 amostras. As amostras tiveram $1 / 2$ do seu comprimento fixado na areia e mantido um espaçamento de $7 \mathrm{~cm}$ (entre blocos) x $6 \mathrm{~cm}$ (entre amostras) (Figura 2a).

A colônia de cupins ficou disposta em uma grelha de $30 \times 40 \mathrm{~cm}$, apoiada em dois tijolos de oito furos, postos sobre a camada de areia contida na caixa (Figura 2b). As amostras ficaram expostas à ação dos cupins durante 20 dias, em uma sala climatizada $\left(27 \pm 2{ }^{\circ} \mathrm{C}\right.$ e $75 \pm 5 \%$ de umidade relativa); após o ensaio, as amostras foram secas (item 2.1) e pesadas.

Foi avaliada a resistência da madeira em função da perda de massa e do desgaste provocado pelos cupins nos corpos-de-prova. A perda de massa foi corrigida por meio de três amostras, para cada retenção, que foram submetidas às mesmas condições de ensaio, porém sem a presença de cupins (perda de massa operacional).

\subsection{Avaliação dos resultados}

Os valores em porcentagem de perda de massa e mortalidade foram transformados em arcsen [raiz quadrada (perda de massa/100)] e os de desgaste (nota) e de tempo (dias) para morte dos cupins em raiz quadrada (nota ou dias + 0,5), para permitir a homogeneidade das variâncias (STELL \& TORRIE, 1980).

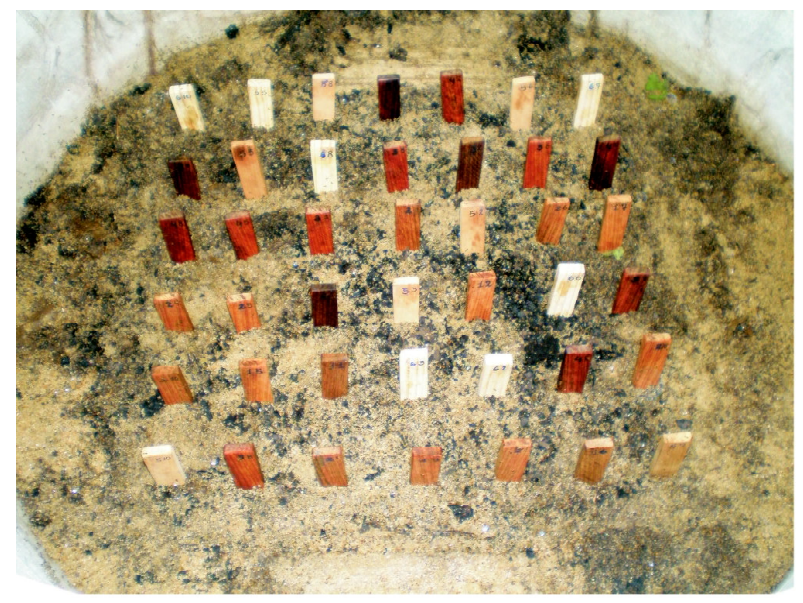

(a)

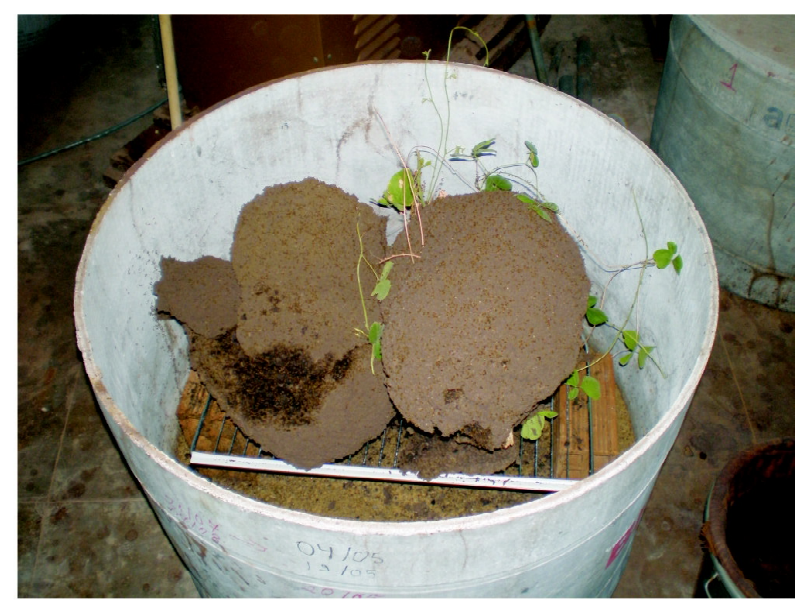

(b)

Figura 2 - Amostras de madeira (a) e colônias de cupins (b) dispostas na caixa.

Figure 2 - Wood test samples (a) and colonies of termites (b) disposed in the box.

Cerne, Lavras, v. 16, n. 2, p. 217-225, abr./jun. 2010 
$\mathrm{Na}$ análise e avaliação dos ensaios foram empregados gráficos e as equações ajustadas para os fatores detectados como significativos pelo teste de F.

\section{RESULTADOS E DISCUSSÕES}

\subsection{Ensaio de alimentação Forçada}

As retenções $\left(\mathrm{kg}\right.$ de óleo $/ \mathrm{m}^{3}$ de madeira) obtidas (Tabela 2) foram próximas as retenções metas propostas para o ensaio (item 2.1). Para a retenção de $10,61 \pm 1,40 \mathrm{~kg} / \mathrm{m}^{3}$ observa-se um decréscimo nos valores de perda de massa da ordem de $19,93 \%$, o que corresponde a um ganho de 76,98\% na resistência da madeira, quando comparada à testemunha (madeira não-tratada, retenção zero). Para essa mesma retenção, obteve-se incremento da nota do desgaste de 3,17 $\pm 0,29$ para $8,31 \pm 1,50$ (ataque intensivo, havendo ruptura de algumas amostras para ataque superficial a moderado), um acréscimo na mortalidade dos cupins de $31,71 \pm 20,06 \%$ para $96,00 \pm$ $10,58 \%$ (mortalidade baixa para mortalidade alta), conforme ASTM D - 3345 (ASTM, 2005b) e um decréscimo de, aproximadamente 15 dias para a morte dos cupins.

O número de dias para a morte dos cupins é considerado por Jankowsky (1986) e Paes (1997), como um bom indicativo da eficiência do produto preservativo para proteger a madeira contra o ataque de cupins, pois quando os cupins morrem rapidamente significa que a substância química foi letal aos insetos (PAES et al., 2003).

A partir da retenção de $10,61 \pm 1,40 \mathrm{~kg} / \mathrm{m}^{3}$, obtevese melhorias na resistência da madeira de sumaúma para todos os parâmetros analisados, indicando que a retenção do óleo de candeia para prevenir o ataque de cupins deve estar entre 10,61 e $16,73 \mathrm{~kg} / \mathrm{m}^{3}$.

Os resultados (Tabela 2) indicam que o óleo de candeia foi eficiente contra o ataque de cupins. Isso reforça a tese da madeira de candeia ser bastante procurada pelos agricultores do Sul de Minas Gerais, para a sua utilização na confecção de cercas (SCOLFORO et al., 2002).

A madeira de Pinus sp., utilizada como padrão de comparação (ASTM, 2005b) sofreu perda de massa de $2,97 \pm 0,28 \%$; desgaste (nota) de 9,00 $\pm 0,28$; e causou a mortalidade de $100 \%$ dos cupins, aos 8 dias de ensaio. Indicando que os cupins empregados não tinham o hábito de consumir a madeira de Pinus sp., uma vez que os mesmos eram provenientes de colônias instaladas em uma árvores de Leucaena leucocephala, da utilização da madeira de sumaúma, em várias instalações e do pouco uso da madeira de Pinus sp. na região. Supriana (1985) afirma que os cupins são muito seletivos na sua dieta, não atacando espécies com as quais têm pouco contato. Observação semelhante foi relatada por Paes et al. (1998).

O resumo das análises de variância, para o delineamento estatístico considerado, para a perda de massa (\%), desgaste (nota), mortalidade (\%) e tempo (dias) é apresentado na Tabela 3. Observa-se que o efeito da retenção foi significativo em nível de $1 \%$ de probabilidade, para todas as variáveis consideradas.

Os gráficos com as relações funcionais estimadas entre as retenções testadas e a perda de massa, retenções e desgaste (nota), retenções e mortalidade e retenções e tempo (dias) para a morte dos cupins são apresentados nas Figuras 3, 4, 5 e 6, respectivamente.

Observa-se, na Figura 3, que ocorreu redução rápida da perda de massa com o aumento da retenção, e que retenções da ordem de 10 a $16 \mathrm{~kg} / \mathrm{m}^{3}$ foram suficientes para proteger a madeira de sumaúma do ataque do cupim testado, por terem conferido a uma madeira de baixa resistência natural, valores de resistência semelhantes

Tabela 2 - Valores médios da retenção $\left(\mathrm{kg} / \mathrm{m}^{3}\right)$, perda de massa (\%), desgaste (nota), mortalidade (\%) e tempo (dias) para morte dos cupins.

Table 2 - Medium values of retention ( $\mathrm{kg} / \mathrm{m}^{3}$ ), loss of mass (\%), waste (note), mortality (\%) and time (days) to death of termites.

\begin{tabular}{ccccc}
\hline $\begin{array}{c}\text { Retenção } \\
\left(\mathrm{kg} / \mathrm{m}^{3}\right)\end{array}$ & $\begin{array}{c}\text { Perda de Massa } \\
(\%)\end{array}$ & $\begin{array}{c}\text { Desgaste } \\
(\text { Nota })\end{array}$ & $\begin{array}{c}\text { Mortalidade } \\
(\%)\end{array}$ & $\begin{array}{c}\text { Tempo } \\
(\text { Dias })\end{array}$ \\
\hline $0,00 \pm 0,00$ & $25,89 \pm 1,86$ & $3,17 \pm 0,29$ & $31,71 \pm 20,06$ & $28,00 \pm 0,00$ \\
$10,61 \pm 1,40$ & $5,96 \pm 3,96$ & $8,31 \pm 1,50$ & $96,00 \pm 10,58$ & $12,57 \pm 7,91$ \\
$16,73 \pm 1,08$ & $1,62 \pm 0,77$ & $9,94 \pm 0,10$ & $100,00 \pm 0,00$ & $8,14 \pm 1,57$ \\
$22,04 \pm 1,40$ & $1,49 \pm 2,30$ & $9,89 \pm 0,11$ & $100,00 \pm 0,00$ & $8,43 \pm 1,62$ \\
$26,94 \pm 1,52$ & $0,32 \pm 0,49$ & $9,89 \pm 0,11$ & $100,00 \pm 0,00$ & $8,43 \pm 0,79$ \\
\hline Pinus $\mathrm{sp}$. & $2,97 \pm 0,28$ & $9,00 \pm 0,28$ & $100,00 \pm 0,00$ & $8,00 \pm 0,00$ \\
\hline
\end{tabular}


Tabela 3 - Resumo das análises de variância para perda de massa (\%), desgaste (nota), mortalidade (\%) e tempo (dias) para morte dos cupins. Dados transformados em arcsen [raiz quadrada (perda de massa ou mortalidade/100)] ou raiz quadrada (nota ou dias $+0,5)$.

Table 3 - Summary of variance analyzes to loss of mass (\%), waste (note), mortality (\%) and time (days) to death of termites. Data transformed in arcsine [square root (loss of mass or mortality/100)] or square root (note or days +0.5 ).

\begin{tabular}{lccccc}
\hline & & \multicolumn{4}{c}{ Quadrados Médios } \\
\cline { 3 - 6 } Fontes de Variação & Graus de Liberdade & $\begin{array}{c}\text { Perda de massa } \\
(\%)\end{array}$ & $\begin{array}{c}\text { Desgaste } \\
(\text { Nota })\end{array}$ & $\begin{array}{c}\text { Mortalidade } \\
(\%)\end{array}$ & $\begin{array}{c}\text { Tempo } \\
\text { (Dias) }\end{array}$ \\
\hline Retenção & 4 & $0,280^{* *}$ & $2,268^{* *}$ & $1,345^{* *}$ & $7,407^{* *}$ \\
Resíduos & 30 & $0,404 \times 10^{-2}$ & 0,172 & 0,021 & 0,245 \\
\hline Coeficiente de variação & 31,507 & 4,507 & 11,859 & 13,954 \\
\hline
\end{tabular}

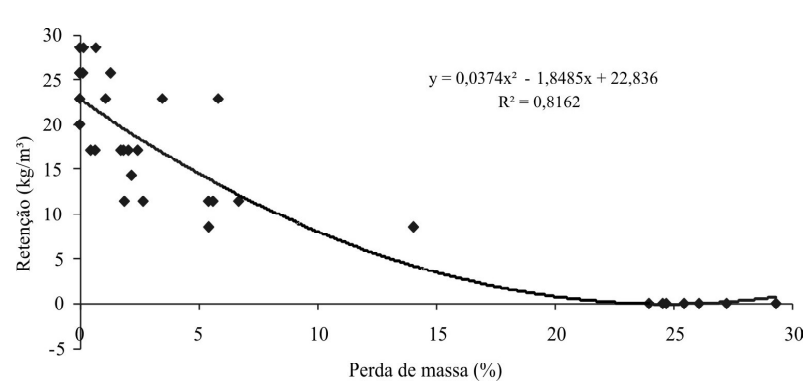

Figura 3 - Relação funcional entre retenção de óleo $\left(\mathrm{kg} / \mathrm{m}^{3}\right)$ e perda de massa $(\%)$ da madeira causada pelo ataque dos cupins.

Figure 3 - Functional relation between oil retention $\left(\mathrm{kg} / \mathrm{m}^{3}\right)$ and loss of mass (\%) of wood caused by termites attack.

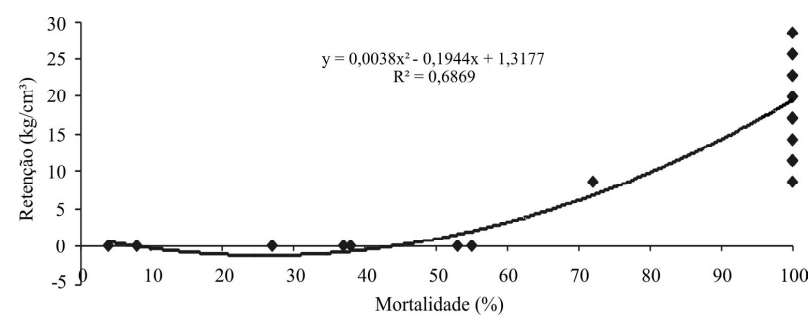

Figura 5 - Relação funcional entre retenção de óleo $\left(\mathrm{kg} / \mathrm{m}^{3}\right)$ mortalidade (\%) dos cupins.

Figure 5 - Functional relation between oil retention $\left(\mathrm{kg} / \mathrm{m}^{3}\right)$ and mortality of termites (\%).

aos obtidos para as madeiras de algaroba (Prosopis juliflora), angico (Anadenanthera colubrina var. cebil) (PAES et al., 2003), louro-pardo (Cordia trichotoma), jurema-preta (Mimosa tenuiflora), sabiá (Mimosa caesalpiniifolia) e teca (Tectona grandis) (PAES et al., 2007) consideradas de boa resistência a cupins e ao apodrecimento.

Cerne, Lavras, v. 16, n. 2, p. 217-225, abr./jun. 2010

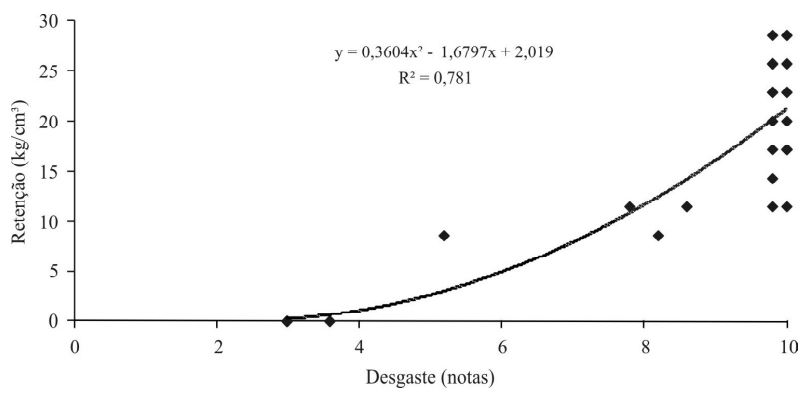

Figura 4 - Relação funcional entre retenção de óleo $\left(\mathrm{kg} / \mathrm{m}^{3}\right)$ e desgaste (notas) da madeira causada pelo ataque dos cupins.

Figure 4 - Functional relation between oil retention $\left(\mathrm{kg} / \mathrm{m}^{3}\right)$ and waste (notes) of wood caused by termites attack.

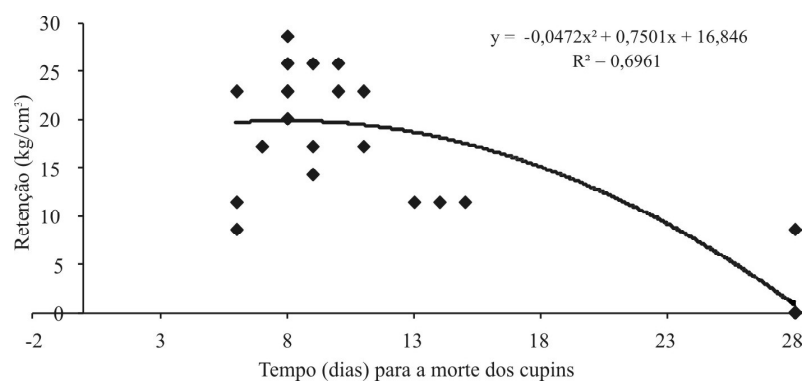

Figura 6 - Relação funcional entre retenção de óleo $\left(\mathrm{kg} / \mathrm{m}^{3}\right)$ e tempo (dias) para a morte dos cupins.

Figure 6 - Functional relation between oil retention $\left(\mathrm{kg} / \mathrm{m}^{3}\right)$ and time (days) to death of termites.

Com relação ao desgaste causado pelos térmitas nas amostras, nota-se efeito semelhante à perda de massa, ou seja, menor desgaste para maiores retenções do óleo de candeia. Retenções da ordem de 10 a $16 \mathrm{~kg} / \mathrm{m}^{3}$ foram suficientes para proteger a madeira, uma vez que os térmitas, praticamente não causaram desgaste nessa faixa. Os valores estão semelhantes aos obtidos por Paes et al. 
(2003, 2007) para as madeiras de boa resistência a cupins e ao apodrecimento.

O comportamento da mortalidade e do número de dias para a morte dos cupins são apresentados nas Figuras 5 e 6, respectivamente. Na Figura 5, verifica-se que retenções da ordem de $10 \mathrm{~kg} / \mathrm{m}^{3}$ causaram mortalidade total dos térmitas, enquanto as da ordem de $16 \mathrm{~kg} / \mathrm{m}^{3}$ (Figura 6) a mortalidade total em menos de 13 dias. O mesmo comportamento foi observado para as retenções mais elevadas. O tempo para morte dos cupins foi semelhante ao obtido por Paes et al. (2003) para as madeiras de aroeira (Myracrodruon urundeuva), braúna (Schinopsis brasiliensis), pau d'arco (Tabebuia impetiginosa) e pereiro (Aspidosperma pyrifolium), que foram as mais resistentes ao ataque de cupins subterrâneos.

\subsection{Ensaio de preferência alimentar}

Esse ensaio estava previsto para ser desativado após 45 dias de sua instalação, conforme trabalhos realizados por Paes et al. (2006a,b, 2007). Porém, em função da morte da colônia de cupins, por inanição ou do efeito do óleo de candeia, o ensaio foi desativado após 20 dias. Esse período de tempo foi o suficiente para que os corpos-de-prova não-tratados (testemunha, retenção zero) fossem completamente consumidos pelos cupins e os confeccionados com madeira de Pinus sp., utilizada como padrão de comparação com outros trabalhos em que ela é empregada, conforme a determinação da ASTM D - 3345 (ASTM, 2005b), sofressem uma perda de massa de 72,17 \pm $7,48 \%$, havendo falhas e rupturas em todos os corpos-deprova (Tabela 4), o que, normalmente, não ocorre quando são oferecidas aos cupins outras fontes de alimento, fato observado por Paes et al. (2006a,b, 2007).

As retenções obtidas para este ensaio foram de $38,35 \pm 5,87 ; 58,22 \pm 1,02 ; 87,53 \pm 2,86 ;$ e $108,36 \pm 13,48 \mathrm{~kg}$ $\mathrm{de}$ óleo/ $\mathrm{m}^{3}$ de madeira, estando próximas às retenções metas propostas para este ensaio (item 2.1). Essas retenções proporcionaram à madeira, ganhos em resistência da ordem de 94,56 a $97,92 \%$ e desgaste, no intervalo de 8,43 a 10,00 (Tabela 4), indicando que, para as retenções testadas, os cupins, praticamente não consumiram a madeira tratada.

As analises de variância (Tabela 5) indicaram que houve diferenças significativas a $1 \%$ de probabilidade entre as retenções testadas, para a perda de massa e desgaste, porém não se observaram diferenças entre os blocos, indicando que a disposição dos corpos-de-prova na caixa (Figura 2) não influenciou no ataque dos cupins.

Os gráficos com as relações funcionais estimadas entre as retenções testadas e a perda de massa e as retenções e desgaste (nota) são apresentados nas Figuras 7 e 8 , respectivamente.

Observa-se, na Figura 7, que retenções da ordem de 30 a $40 \mathrm{~kg} / \mathrm{m}^{3}$ foram suficientes para proteger a madeira de sumaúma do ataque do cupim testado. Como a perda de massa para essa faixa de retenção foi de $5,44 \%$, o desgaste de 8,43 e a colônia sucumbiu após 20 dias, o que, normalmente, não ocorre, indicando que retenções na faixa de 10 a $16 \mathrm{~kg}$ de óleo $/ \mathrm{m}^{3}$ de madeira seriam suficientes para prevenir o ataque de cupins em estruturas confeccionadas com a madeira de sumaúma.

O ganho na resistência da madeira, proporcionado pelo tratamento (retenção de 10 a $16 \mathrm{~kg} / \mathrm{m}^{3}$ ), foi capaz de conferir à madeira de sumaúma, comportamento semelhante ao das madeiras de algaroba (Prosopis juliflora), angico (Anadenanthera colubrina var. cebil), aroeira (Myracrodruon urundeuva), braúna (Schinopsis brasiliensis), pau d'arco (Tabebuia impetiginosa), pereiro (Aspidosperma pyrifolium) (PAES et al., 2001), louro-pardo (Cordia trichotoma), jurema-preta (Mimosa tenuiflora), sabiá (Mimosa caesalpiniifolia) e teca (Tectona grandis) (PAES et al., 2007), que foram as mais resistentes ao ataque de cupins subterrâneos em ensaio de preferência alimentar.

Tabela 4 - Valores médios da retenção $\left(\mathrm{kg} / \mathrm{m}^{3}\right)$, perda de massa $(\%)$ e desgaste (nota) causado pelos cupins.

Table 4-Medium Values of retention ( $\left.\mathrm{kg} / \mathrm{m}^{3}\right)$, loss of mass (\%) and waste (note) caused by termites.

\begin{tabular}{ccc}
\hline Retenção $\left(\mathrm{kg} / \mathrm{m}^{3}\right)$ & Perda de Massa $(\%)$ & Desgaste (Nota) \\
\hline $0,00 \pm 0,00$ & $100,00 \pm 0,00$ & $0,00 \pm 0,00$ \\
$38,35 \pm 5,87$ & $5,44 \pm 2,03$ & $8,43 \pm 1,36$ \\
$58,22 \pm 1,02$ & $3,92 \pm 0,75$ & $9,69 \pm 0,36$ \\
$87,53 \pm 2,86$ & $2,89 \pm 0,66$ & $9,83 \pm 0,29$ \\
$108,36 \pm 13,48$ & $2,08 \pm 0,96$ & $10,00 \pm 0,00$ \\
\hline Pinus sp. & $72,17 \pm 7,48$ & $0,00 \pm 0,00$ \\
\hline
\end{tabular}


Tabela 5 - Resumo das analises de variância para perda de massa (\%) e desgaste (nota). Dados transformados em arcsen [raiz quadrada (perda de massa/100)] ou raiz quadrada (nota $+0,5)$.

Table 5 - Summary of variance analyzes to loss of mass (\%) and waste (note). Data transformed in arcsine [square root (loss of mass/100)] or square root (note +0.5$)$.

\begin{tabular}{lccc}
\hline \multirow{2}{*}{ Fontes de Variação } & Graus de Liberdade & \multicolumn{2}{c}{ Quadrados Médios } \\
\cline { 3 - 4 } & & Perda de Massa & Desgaste \\
\hline Blocos & 6 & $0,407 \times 10^{-3}$ NS & $0,013^{\mathrm{NS}}$ \\
Retenções & 4 & $2,694 * *$ & $8,449^{* *}$ \\
Resíduos & 24 & $0,927 \times 10^{-3}$ & 0,012 \\
\hline Coeficiente de variação & & 6,590 & 4,175 \\
\hline
\end{tabular}

** Significativo a $1 \%$ de probabilidade; ${ }^{\text {NS }}$ Não significativo a $5 \%$ de probabilidade.

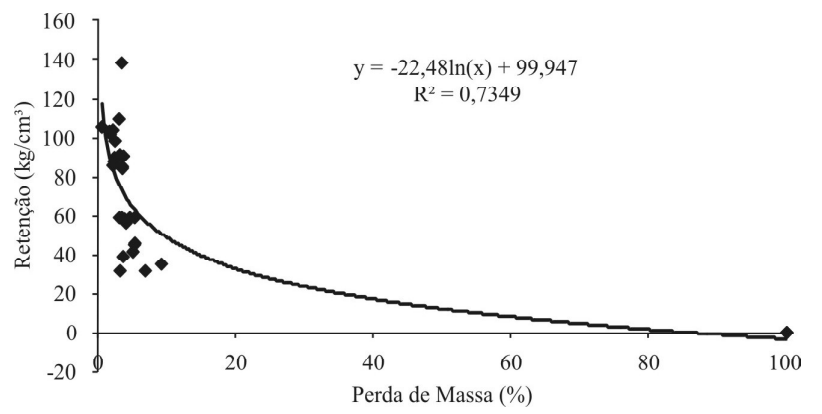

Figura 7 - Relação funcional entre retenção de óleo $\left(\mathrm{kg} / \mathrm{m}^{3}\right)$ e perda de massa (\%) da madeira causada pelo ataque dos cupins.

Figure 7 - Functional relation between oil retention $\left(\mathrm{kg} / \mathrm{m}^{3}\right)$ and loss of mass (\%) of wood caused by termites attack.

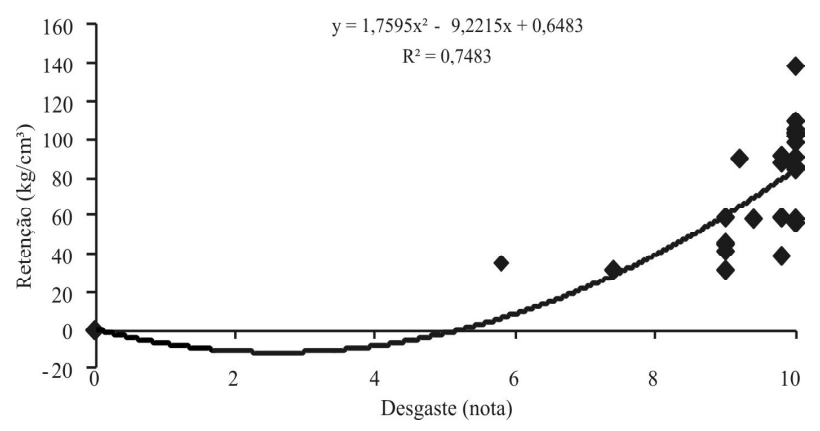

Figura 8 - Relação funcional entre retenção de óleo $\left(\mathrm{kg} / \mathrm{m}^{3}\right)$ e desgaste (notas) da madeira causada pelo ataque dos cupins.

Figure 8 - Functional relation between oil retention $\left(\mathrm{kg} / \mathrm{m}^{3}\right)$ and waste (notes) of wood caused by termites attack.

Com relação aos valores de desgaste (notas), observa-se, na Figura 8, que as retenções na ordem de 30 a $40 \mathrm{~kg} / \mathrm{m}^{3}$ foram suficientes para proteger a madeira de sumaúma do ataque do cupim testado.

Cerne, Lavras, v. 16, n. 2, p. 217-225, abr./jun. 2010
Em função das notas de desgaste superiores a nove, em sua maioria, o que confere à madeira de sumaúma resistência semelhante a madeiras de alta resistência a cupins xilófagos (PAES et al., 2001, 2007) e da mortalidade da colônia em contato com a madeira tratada, indicam que retenções de 10 a $16 \mathrm{~kg} / \mathrm{m}^{3}$ seriam suficientes para garantirem boa resistência à madeira tratada.

\section{CONCLUSÕES}

O óleo de candeia (Eremanthus erythropappus (DC.) Macleish.), nas retenções de 10,61 a 16,73 kg/m (ensaio de alimentação forçada) e 38,35 a $58,22 \mathrm{~kg} / \mathrm{m}^{3}$ (ensaio de preferência alimentar), foi suficiente para incrementar a resistência da madeira de sumaúma (Ceiba pentandra (L.) Gaertn.) inibindo o ataque dos cupins.

Nas retenções superiores a $16,73 \mathrm{~kg} / \mathrm{m}^{3}$ (ensaio de alimentação forçada) e a $58,22 \mathrm{~kg} / \mathrm{m}^{3}$ (ensaio de preferência alimentar), o óleo de candeia preveniu o ataque da madeira testada, inviabilizando o acesso dos cupins à fonte de alimento.

O óleo de candeia, em função do seu custo, é inviável para o tratamento de madeiras para o meio rural, mas poderia ser utilizado no tratamento de madeiras para fins mais nobres, como na construção civil, onde um produto natural poderia ser aplicado sem apresentar risco ao homem e ao ambiente.

Em função da eficiência do óleo de candeia contra cupins xilófagos, retenções da ordem de $10,61 \mathrm{~kg} / \mathrm{m}^{3}$ já seriam suficientes para prevenir o ataque de cupins em estruturas diversas, como escadas, armários embutidos, batentes de portas e janelas.

Resultados conclusivos são necessários para verificar a viabilidade técnica e econômica do emprego do óleo de candeia como preservativo natural para inibir o 
ataque de cupins xilófagos em peças de madeira empregadas em estruturas diversas.

\section{REFERÊNCIAS BIBLIOGRÁFICAS}

AMERICAN SOCIETY FOR TESTING AND MATERIALS. ASTM D - 1413: standard test method for wood preservatives by laboratory soil-block cultures. Philadelphia, 2005a. 7 p.

AMERICAN SOCIETY FOR TESTING AND MATERIALS. ASTM D - 3345: standard method for laboratory evaluation of wood and other cellulosic materials for resistance to termite. Philadelphia, 2005b. 3 p.

FARIAS SOBRINHO, D. W. Viabilidade técnica e econômica do tratamento preservativo da madeira de algaroba (Prosopis juliflora (Sw) D.C.), pelo método de substituição da seiva. 2003. 53 f. Dissertação (Mestrado em Engenharia Agrícola) Universidade Federal de Campina Grande, Campina Grande, 2003.

HUNT, G. M.; GARRATT, G. A. Wood preservation. 3. ed. New York: McGraw Hill, 1967. 433 p.

JANKOWSKY, I. P. Pontencialidade do creosoto de Eucalyptus spp. como preservaticos para madeiras. 1986. $159 \mathrm{f}$. Tese (Doutorado em Engenharia) - Universidade de São Paulo, São Paulo, 1986.

PAES, J. B. Efeitos da purificação e do enriquecimento do creosoto vegetal em suas propriedades preservativas. 1997. 143 f. Tese (Doutorado em Ciência Florestal) - Universidade Federal de Viçosa, Viçosa, 1997.

PAES, J. B.; MELO, R. R.; LIMA, C. R. Resistência natural de sete madeiras a cupins subterrâneos em ensaio de alimentação forçada. In: ENCONTRO BRASILEIRO EM MADEIRAS E EM ESTRUTURAS DE MADEIRA, 10., 2006, São Pedro. Anais... São Pedro: CEVEMAD/UNESP-IBRAMEM, 2006a. CD-ROM.

PAES, J. B.; MELO, R. R.; LIMA, C. R.; OLIVEIRA, B. Resistência natural de sete madeiras ao cupim subterrâneo (Nasutitermes corniger Motsch.) em ensaio de preferência alimentar. Revista Brasileira de Ciências Agrárias, Recife, v. 2, n. 1, p. 57-62, 2007.
PAES, J. B.; MORAIS, V. M.; FARIAS SOBRINHO, D. W.; BAKKE, O. A. Resistência natural de nove madeiras do SemiÁrido brasileiro a cupins subterrâneos, em ensaio de laboratório. Cerne, Lavras, v. 9, n. 1, p. 36-47, 2003.

PAES, J. B.; MORAIS, V. M.; LIMA, C. R. Resistência natural de nove madeiras do Semi-Árido brasileiro a cupins subterrâneos, em ensaio de preferência alimentar. Brasil Florestal, Brasília, v. 20, n. 72, p. 59-69, 2001.

PAES, J. B.; RAMOS, I. E. C.; FARIAS SOBRINHO, D. W. Eficiência do CCB na resistência da madeira de algaroba (Prosopis juliflora (Sw) D.C.) a cupins subterrâneos (Nasutiternes corniger Motsch.) em ensaio de preferência alimentar. Ambiência, Guarapuava, v. 2, n. 1, p. 51-64, 2006 b.

PAES, J. B.; VITAL, B. R. Resistência natural da madeira de cinco espécies de eucalipto a cupins subterrâneos em testes de laboratório. Revista Árvore, Viçosa, v. 24, n. 1, p. 1-6, 2000.

PAES, J. B.; VITAL, B. R.; DELLA LUCIA, T. M. C.; DELLA LUCIA, R. M. Eficiência do creosoto vegetal contra cupins subterrâneos em testes de laboratório. Revista Árvore, Viçosa, v. 22, n. 1, p. 89-98, 1998.

RICHARDSON, B. A. Wood preservation. 2. ed. London: E \& FN SPON, 1993. 226 p.

SCOLFORO, J. R. S.; OLIVEIRA, A. D.; DAVIDE, A. C.; MELLO, J. M.; ACERBI JUNIOR, F. W. Manejo sustentável da candeia Eremanthus erythropappus e Eremanthus incanus. Lavras: UFLA/FAEPE, 2002. 350 p. Relatório técnico científico.

SCOLFORO, J. R. S.; PÉREZ, J. F. M.; MELLO, J. M.; OLIVEIRA, A. D.; CAMOLESI, J. F.; BORGES, L. F. R.; ACERBI JUNIOR, F. W. Estimativas de volume, peso seco, peso de óleo e quantidade de moirões para a candeia (Eremanthus erythropappus (DC.) MacLeish). Cerne, Lavras, v. 10 n. 1, p. 87-102, 2004.

SUPRIANA, N. Notes the resistance of tropical wood against termites. Stockholm: The International Research Group on Wood Preservation, 1985. 9 p. (Doc. IRG/WP, 1249).

STELL, R. G. D.; TORRIE, J. H. Principles and procedures of statistic: a biometrical approach. 2. ed. New York: McGraw Hill, 1980. 633 p. 
